\title{
Fungi Genus and Concentration in the Air of Onion Fields and Their Opportunistic Action Related to Mycotic Keratitis
}

\author{
CHING-WEN CHANG \\ Institute of Occupational Safety and Health \\ Council of Labor Affairs \\ Taipei, Taiwan, Republic of China \\ CHI-KUNG HO \\ Department of Occupational Medicine \\ Kaohsiung Medical University Hospital \\ and \\ Graduate Institute of Occupational Safety and Health \\ Kaohsiung Medical University \\ Kaohsiung, Taiwan, Republic of China \\ ZUEI-CHING CHEN \\ Department of Botany \\ National Taiwan University \\ Taipei, Taiwan, Republic of China \\ YAW-HUEI HWANG \\ Institute of Occupational Medicine and Industrial \\ Hygiene \\ National Taiwan University \\ Taipei, Taiwan, Republic of China
}

\author{
CHEN-YANG CHANG \\ SHAO-TAUN LIU \\ Department of Occupational Medicine \\ Kaohsiung Medical University Hospital \\ Kaohsiung, Taiwan, Republic of China \\ MEI-JU CHEN \\ Graduate Institute of Occupational Safety and Health \\ Kaohsiung Medical University \\ Kaohsiung, Taiwan, Republic of China \\ MAO-YEN CHEN \\ Department of Botany \\ National Taiwan University \\ Taipei, Taiwan, Republic of China
}

\begin{abstract}
The authors determined fungi concentrations and genera from onion fields located in monsoon and nonmonsoon areas of Taiwan, as well as concentrations from a county housing location, which served as the comparison site. The authors explored the relationship(s) among onion harvesting, monsoon characteristics, airborne fungal levels, and mycotic eye infection. Airborne fungal levels in the onion field in the nonmonsoon area were the highest, followed by decreasing levels in the monsoon area and control sites, regardless of the sampling periods. The geometric mean of airborne fungal concentrations was the highest during onion harvesting. Cladosporium was the most dominant fungus during pre- and postharvest seasons, whereas Aspergillus, Fusraium, Acremonium, Alternaria, Penicillium, Monilia, Mycelia, and Rhizopus were increased significantly during harvesting. Although fungal concentrations in monsoon onion fields were lower than concentrations measured in the nonmonsoon area, the invasion of dangerous fungal pathogens following eye trauma by airborne sharp exotics (e.g., onion flakes) dispersed in high wind may account for the increase in corneal ulcer cases that occur in the monsoon area.

$<$ Key words: fungi, mycotic keratitis, onion>
\end{abstract}

MYCOTIC KERATITIS, or keratomycosis, can lead to a significant reduction in vision. Cases of mycotic keratitis have been reported in children, ${ }^{1}$ but most cases are associated with outdoor agriculture activities. ${ }^{2-4}$ Trauma, typically resulting from vegetation, is the common predisposing factor. ${ }^{2-5}$ Other factors, such as ster- oid therapy for intraocular surgery and chronic ocular inflammation, might also contribute to corneal mycotic infections. ${ }^{6}$

Most studies on mycotic keratitis report the fungi genera isolated from the eyes of patients., ${ }^{1,10}$ The fungi genera include Aspergillus, Acremonium, Fusarium, Al- 
ternaria, Curvularia, Penicillium, Tetraploa, and Candida. However, knowledge of the ecological distribution of fungal genera in agriculture fields associated with mycotic keratitis is very limited. ${ }^{11}$

Recently, 5 onion harvesters in the Heng-Chun Peninsula of southern Taiwan simultaneously reported suffering from fungal corneal ulcers. ${ }^{12}$ Four of the 5 cases complained of ocular trauma from pieces of onion skin or plant leaves that drifted into their eyes while they were harvesting onions. The researchers used corneal scraping to clinically identify the fungi in the injured eyes of all 5 cases. Three patients received penetrating keratoplasty, whereas the remaining 2 recovered following treatment with Amphotericin B and Fluconazole. The authors indicated that their study was the first report of a group of fungal corneal ulcer cases associated with onion-harvesting activities, and they considered the unique atmospheric characteristic of strong monsoons, which blew during the onion harvest season, and to be a contributing factor of eye trauma. As is the case in most reports of corneal mycotic infection, fungal genera identified from the eyes of 4 of the patients included Candida, Cephalosporium, and Cryptococcus. However, information about the ecological distribution of fungal genera in the onion fields was not provided. To evaluate the possible link between fungal corneal ulcer cases and occupational environments and atmospheric characteristics, we conducted the present study. We sought to determine the variations and concentrations of airborne fungal genera that existed during a period of onion growth in 2 separate geographic areas characterized by differing atmospheric characteristics of monsoons. The association between fungi occurrence and potential ocular infection of onion harvesters is also discussed.

\section{Materials and Method}

Environments. The major cultivated onion farmlands in Taiwan are located in 4 southern-end townships: (1) Lin-Yuan, (2) Heng-Chun, (3) Shen-Chen, and (4) FongKung. Lin-Yuan is a suburban township located approximately $70 \mathrm{~km}$ south of metropolitan Kaohsiung city. There are no strong monsoons in the Lin-Yuan area. Heng-Chun, Shen-Chen, and Fong-Kung are typical rural townships, surrounded by mountains and sea, in the Heng-Chun Peninsula. Downslope wind storms occur from October to April southeasterly across the central mountain chain of Taiwan. According to the local meteorological records of the Heng-Chun area, the monthly average wind velocity during the periods January-April 1988 and October-December 1998 was, for example, $2.8-5.9 \mathrm{~m} / \mathrm{sec}(6.3-13.2 \mathrm{mph})$. The maximum wind velocity (10-min average) is 10.1-16.2 $\mathrm{m} / \mathrm{sec}$ (22.6-36.2 $\mathrm{mph}$ ), and the instant maximum wind velocity can reach $20.6-32.4 \mathrm{~m} / \mathrm{sec}(46.1-72.5 \mathrm{mph}) .^{13}$ The period for onion growth and harvest is usually from November to April (i.e., within the monsoon season).

Air sampling strategy and procedures. The authors randomly selected 1 onion field from each of the 4 townships to be the exposed sites, which represented a nonmonsoon field (Lin-Yuan) and 3 monsoon fields
(Heng-Chun, Shen-Chen, and Fong-Kung). All selected fields were distant from traffic roads and the residential community, and the fields were surrounded by other onion fields. An outdoor parking lot at a residence located in the rural township of Fung-Leu served as the comparison site.

Fungal samples were collected from the air of the 4 selected fields and from the comparison site-before, during, and after onion harvesting. Air samples were also taken simultaneously at harvest from 3 onion-gathering sites, respectively, located (a) in the middle of an onion field; (b) in an outdoor, barren area that was not adjacent to the aforementioned onion field; and (c) in an indoor gathering-distribution house.

For every sampling period, 30 airborne fungi samples were collected at $80 \mathrm{~cm}$ above the ground at the center and 4 corners of the selected onion fields. Measurement was achieved with a single-stage Andersen Microbial Sampler (AMS, Graseby [Smyrna, Georgia]), which operated at $28.3 \mathrm{I} / \mathrm{min}$. Six samples were collected simultaneously at each sampling site (i.e., 6 AMSs at 3 different sampling times). The sampling times for the preharvest survey were set at $5 \mathrm{~min}, 10 \mathrm{~min}$, and 15 min, whereas sampling times for harvest and postharvest measurements were set at $1 \mathrm{~min}, 2 \mathrm{~min}$, and $5 \mathrm{~min}$. The AMSs were preautoclaved in the laboratory and disinfected with $70 \%$ ethanol-immersed cotton balls between each sampling. Fungi were collected directly onto plates containing $20 \mathrm{ml}$ of Sabouraud dextrose agar with $40 \mu \mathrm{g} / \mathrm{ml}$ chloramphenicol (SDAC, Difco Laboratory [Detroit, Michigan]). Calibration of airflow was performed before and after sampling occurred. Two field blank samples were also taken from the field. Sampling at the parking lot was conducted in a manner that was similar to the procedures used at the other sites.

The sampling plates were sealed, sent back to the laboratory by express mail, and incubated at $25^{\circ} \mathrm{C}$ for 4-7 days. Colonies that formed on the plates were then counted. The positive-hole method was applied to the AMS samples for correction of microbial coincidence. ${ }^{14}$ Fungal colonies on plates were examined under a dissecting microscope (model SZ-PT, Olympus [Tokyo, Japan]). The spores of each colony were then picked and examined under a high-resolution microscope (model $\mathrm{BH}-2$, Olympus [Tokyo, Japan]) for identification of genus in accordance with available references ${ }^{15,16} \mathrm{~A}$ total of 279 air samples were used for additional data analysis.

Environmental factors. Temperature, wind velocity, and relative humidity were recorded with direct-reading instruments (Testo, GmbH\&Co. [Lenzkirch, Germany]) on each sampling day. At least 3 readings were recorded at each sampling site.

Statistical analysis. Airborne concentrations of culturable fungi were determined by dividing the corrected colony number by the volume of sampled air. The values were then calculated and expressed as geometric means with standard deviations. The percentage of an individual fungal genus was calculated as 100 times a ratio of concentration of an individual genus to the culturable fungi in all of the samples. 


\section{Results}

Table 1 illustrates the concentrations of atmospheric fungi from the onion farmlands and parking lot before, during, and after onion harvesting. Regardless of the sampling periods, the geometric mean concentrations of airborne fungi at the nonmonsoon onion farmland were always the highest, followed by concentrations determined from the farmlands in the monsoon areas and the parking lot. We also observed that, in all of the farmlands measured, the mean fungi concentration was increased significantly when onions were harvested. The increased levels, shown as the harvest/before harvest $(\mathrm{H} / \mathrm{BH})$ values in Table 1 , were 2.7 for nonmonsoon farmland and 3.7-6.8 for monsoon sites. Once the onions were harvested, all airborne fungi levels were decreased-but to different degrees, compared with levels present before harvesting.

Significantly high fungal levels were identified at onion-gathering sites (Table 1). A mean of 9,063.9 colony-forming units $(\mathrm{CFU}) / \mathrm{m}^{3}$ existed at an outdoor onion-gathering ground in Heng-Chun. This value is 6.6 times the average of airborne fungi $(1,363.6$ $\mathrm{CFU} / \mathrm{m}^{3}$ ) at the onion farm in the same township, measured during the same sampling day. In Heng-Chun, an elevated fungal level of $6,999.1 \mathrm{CFU} / \mathrm{m}^{3}$ was also found in the air of an indoor house designated for onion gathering and distribution. Given the unexpected abundance, most of samples collected from both sites could not be enumerated and were, therefore, discarded prior to data analysis. On the other hand, a temporary gathering site at the center of an onion farm in Fong-Kung did not have an elevated fungal level; rather, its fungal concentration of $427.9 \mathrm{CFU} / \mathrm{m}^{3}$ was lower than the mean of that onion farmland $\left(922.6 \mathrm{CFU} / \mathrm{m}^{3}\right)$.

The genus-specified concentrations of airborne fungi are presented in Table 2. With respect to the nonmon- soon onion farmland, Cladosporium was the most predominant genus before, during, and after harvesting, accounting for $92 \%, 59 \%$, and $85 \%$, respectively. In the period of onion harvesting, mean concentrations of Aspergillus, Mycelia, and Fusarium were increased 30.9-, $15.2-$, and 22-fold, respectively, compared with preharvesting concentrations, and they accounted for $24 \%$, $8 \%$, and $6 \%$, respectively, of airborne fungi flora. Airborne Acremonium concentration in the harvesting period was also 10.2 times the level determined at the time of preharvesting, but it was nonetheless present in a relatively low concentration of $3.9 \mathrm{CFU} / \mathrm{m}^{3}$.

In monsoon area onion farmlands, Cladosporium was dominant in pre- and postharvesting periods, accounting for $55-56 \%$ of the airborne fungi; $22-29 \%$ of airborne fungi were identified as Aspergillus. During onion harvesting, Aspergillus was greatly aerosolized, resulting in an increase of 7.6 times the concentration at preharvesting, and it represented $38 \%$ of the airborne fungi, which was even higher than the percentage of Cladosporium (30\%). Other frequently identified fungi included Fusarium (11\%), Mycelia (8\%), and Penicillium $(8 \%)$, with concentrations increased by $5-, 7-$, and 5.7-fold, respectively. Airborne Acremonium and Rhizopus concentrations were also increased by 14.4 -fold, respectively, during onion harvesting, but both levels were comparatively low. Almost all of the observed fungi were reduced or unidentified in the air of farmlands after onions were cropped, except for Trichoderma, Curvalaria, and Candida. The latter 2 were found only in postharvesting samples-at rather low concentrations.

One of the significant findings in the parking lot during the harvest period was the identification of abundant airborne Candida (35\%) and other yeasts (24\%). In addition, in contrast to the results of onion fields, Fusarium, Mycelia, and Acremonium were all slightly dimin-

Table 1.-Concentration of Airborne Fungi Measured at 4 Onion Farmlands, 3 Onion Accumulation Sites, and a Parking Lot-Before, During, and After Onion Harvesting

\begin{tabular}{|c|c|c|c|c|c|c|c|c|c|c|c|}
\hline \multirow[b]{2}{*}{ Measurement site/town } & \multicolumn{3}{|c|}{$\begin{array}{l}\text { Before harvesting } \\
\qquad(\mathrm{BH})\end{array}$} & \multicolumn{3}{|c|}{$\begin{array}{l}\text { Harvesting } \\
(\mathrm{H})\end{array}$} & \multicolumn{3}{|c|}{$\begin{array}{l}\text { After harvesting } \\
\qquad(\mathrm{AH})\end{array}$} & \multicolumn{2}{|c|}{$\begin{array}{l}\text { Ratio of mean } \\
\text { concentration }\end{array}$} \\
\hline & $G M^{*}$ & $G S D$ & $\bar{n}$ & $G M^{*}$ & $G S D$ & $\bar{n}$ & $G M^{*}$ & $G S D$ & $\bar{n}$ & $\mathrm{H} / \mathrm{BH}$ & $\mathrm{AH} / \mathrm{BH}$ \\
\hline \multicolumn{12}{|l|}{ Onion farmland: } \\
\hline Nonmonsoon area: Lin-Yuan & 913.5 & 2.3 & 19 & $2,485.2$ & 1.7 & 13 & 887.1 & 2.0 & 20 & 2.7 & 1.0 \\
\hline Monsoon areat & 201.4 & 2.7 & 55 & 932.3 & 2.4 & 80 & 557.1 & 1.9 & 60 & 4.6 & 2.8 \\
\hline Heng-Chun & 366.8 & 3.1 & 16 & $1,363.6$ & 2.5 & 21 & 594.0 & 2.1 & 20 & 3.7 & 1.6 \\
\hline Shen-Chen & 188.2 & 2.1 & 18 & 767.3 & 2.4 & 40 & 602.6 & 1.6 & 20 & 4.1 & 3.2 \\
\hline Fong-Kung & 135.1 & 2.4 & 21 & 922.6 & 2.0 & 19 & 483.0 & 2.0 & 20 & 6.8 & 3.6 \\
\hline \multicolumn{12}{|l|}{ Onion-gathering site: } \\
\hline Onion farmland (Fong-Kung) & - & - & - & 427.9 & 2.0 & 12 & - & - & - & - & - \\
\hline Outdoor ground (Heng-Chun) & - & - & - & $9,063.9$ & 1.4 & 2 & - & - & - & - & - \\
\hline Indoor house (Heng-Chun) & - & - & - & $6,999.1$ & 1.3 & 2 & - & - & - & - & - \\
\hline Parking lot (Fung-Leu) & 88.5 & 2.2 & 6 & 899.5 & 1.7 & 6 & 408.0 & 1.3 & 4 & 10.2 & 4.6 \\
\hline
\end{tabular}

Notes: $G M=$ geometric mean, and $G S D=$ geometric standard deviation

*Colony-forming units $/ \mathrm{m}^{3}\left(\mathrm{CFU} / \mathrm{m}^{3}\right)$.

tThe results presented here are a combination of the data collected from the onion farmlands in Heng-Chun, Shen-Chen, and Fong-Kung areas. 


\begin{tabular}{|c|c|c|c|c|c|}
\hline 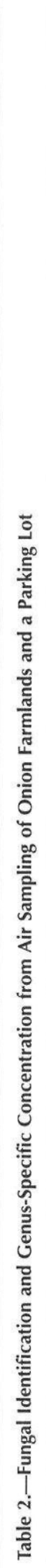 & 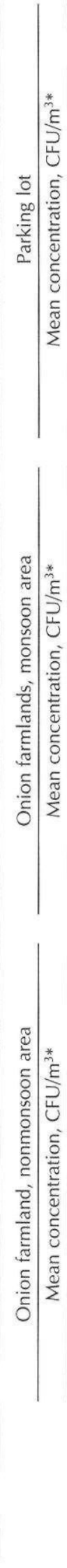 & 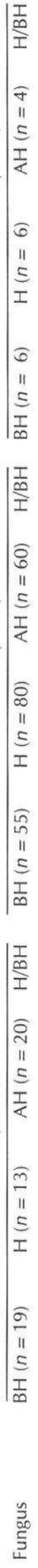 & 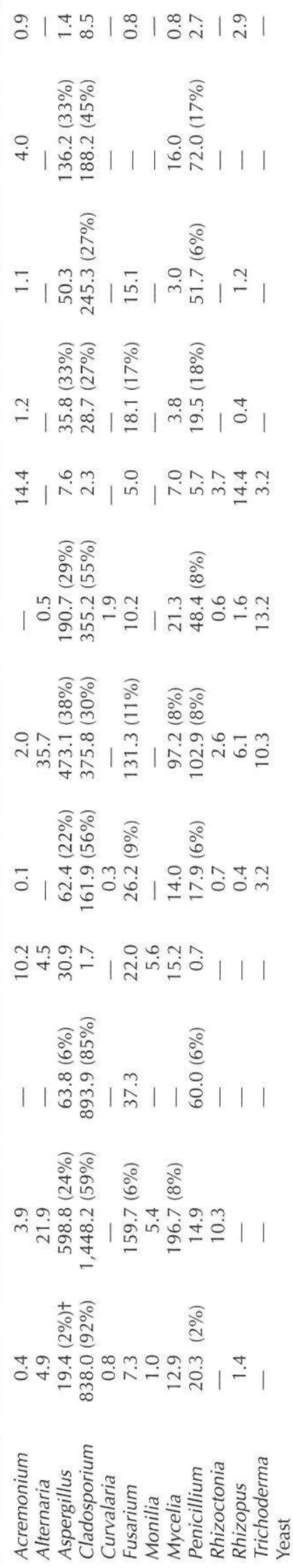 & 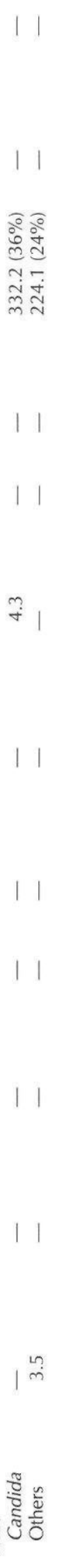 & 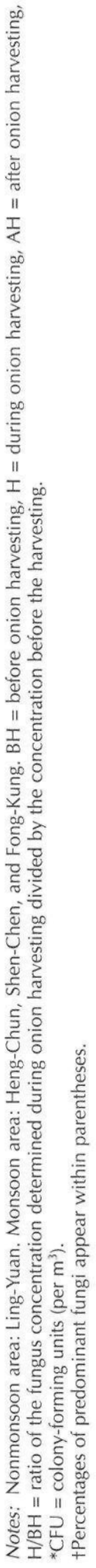 \\
\hline
\end{tabular}


ished during the harvest season. Furthermore, the level of airborne Aspergillus (50.3 CFU $/ \mathrm{m}^{3}$ ) was only approximately $1 / 10$ of levels determined at onion farmlands $\left(473.1 \mathrm{CFU} / \mathrm{m}^{3}\right.$ and $\left.598.8 \mathrm{CFU} / \mathrm{m}^{3}\right)$, and it was not increased appreciably during the harvest season $(\mathrm{H} / \mathrm{BH}$ value $=1.4)$ as shown in the onion farmlands $(\mathrm{H} / \mathrm{BH}$ values $=30.9$ and 7.6). Aspergillus, however, accounted for $33 \%$ of airborne fungi for both pre- and postharvesting seasons. There was a high prevalence of Cladosporium (27-45\%) present in the air, regardless of the sampling periods.

The respective averages of atmospheric wind velocity measured before, during, and after onion harvesting were $1.15 \mathrm{~m} / \mathrm{sec}, 0.95 \mathrm{~m} / \mathrm{sec}$, and $0.74 \mathrm{~m} / \mathrm{sec}$, respectively $(2.57 \mathrm{mph}, 2.13 \mathrm{mph}$, and $1.66 \mathrm{mph}$, respectively) for the nonmonsoon field; $7.98 \mathrm{~m} / \mathrm{sec}, 2.88 \mathrm{~m} / \mathrm{sec}$, and $1.85 \mathrm{~m} / \mathrm{sec}$, respectively $(17.85 \mathrm{mph}, 6.44 \mathrm{mph}$, and $4.14 \mathrm{mph}$, respectively) for the monsoon farmlands; and $0.31 \mathrm{~m} / \mathrm{sec}, 0.68 \mathrm{~m} / \mathrm{sec}$, and $0.53 \mathrm{~m} / \mathrm{sec}$, respectively $(0.69 \mathrm{mph}, 1.52 \mathrm{mph}$, and $1.19 \mathrm{mph}$, respectively) for the parking lot. Mean temperatures of these 3 locations during 3 concomitant sampling occasions were $21.6^{\circ} \mathrm{C}, 24.9{ }^{\circ} \mathrm{C}$, and $32.2^{\circ} \mathrm{C}$, respectively (nonmonsoon field); $26.9{ }^{\circ} \mathrm{C}, 32.2{ }^{\circ} \mathrm{C}$, and $31.3{ }^{\circ} \mathrm{C}$, respectively (monsoon farms); and $29.9^{\circ} \mathrm{C}, 32.9^{\circ} \mathrm{C}$, and $28.8{ }^{\circ} \mathrm{C}$, respectively (parking lot). The corresponding relative humidity was averaged at $62.6 \%, 72.9 \%$, and $71.4 \%$, respectively; $54.3 \%, 66 \%$, and $68 \%$, respectively; and $62.2 \%, 46.3 \%$, and $71.5 \%$, respectively. Monsoon onion fields tended to experience higher wind speed and atmospheric temperatures - but lower relative humidity - than nonmonsoon farmland.

\section{Discussion}

More than 70 species of fungi belonging to 40 genera are reportedly associated with the occurrence of human keratitis, among which Fusarium, Aspergillus, Curvular$i a$, and yeast-like fungi have been identified frequently. ${ }^{2}$ Although many fungi are possible pathogens, the frequent isolates of fungi from eyes of individuals with keratitis vary geographically. For example, Fusarium is the most commonly isolated genus in south Florida, 5,17 whereas Aspergillus is prevalent in India and Thailand. ${ }^{1,18,19}$ Candida has been isolated frequently in Britain, ${ }^{20}$ but it has not been commonly reported as being the cause of keratitis in tropical countries. ${ }^{2}$ Perhaps this difference results from the climate characteristics of various regions. The climate of the present study areas was similar to that in south Florida, India, and Thailand. We observed that, during onion harvesting, the concentrations of Apsergillus and Fusarium were notably increased and prevalent in the air. Inasmuch as Fursarium and Aspergillus may cause moderate to severe outcomes following corneal infection, ${ }^{2}$ the prevalence of relatively high levels of these fungi in the air imposes a potential threat to onion harvesters. Increases in airborne concentrations of other keratitis-related agents, such as Acremonium, Alternaria, and Penicillium, should also be considered as potential hazards.

In addition to the presence of dangerous fungi in onion farmlands during harvest, trauma of eyes caused by exotic bodies, such as onion flakes or dusts, is more likely to occur in monsoon areas with gusty winds. In an animal study, Hwang et al. ${ }^{21}$ demonstrated that onion outer scales may significantly damage the cornea of rats in environments in which the wind velocity exceeds $10 \mathrm{~m} / \mathrm{sec}$; such conditions occur often in monsoon regions during onion planting and harvesting. It is speculated that notably increased levels of dangerous fungi with a likely occurrence of eye trauma during onion-harvest operations would contribute to the incidence of keratitis among onion harvesters in a monsoon area. This implication is supported, in part, by our clinical findings of fungi in the injured corneas of the cluster cases, and by the cases' self-reported statement: "Eye trauma by onion skins or plant leaves during onion harvesting operation."12 [sic] In addition to the environmental characteristics, host factors, including wearing of contact lens, use of mascara, use of certain medications, use of antibiotics and/or corticosteroids, insufficiency of tear secretion, presence of ocular diseases and/or systematic disorders such as diabetes, might also contribute to the development of mycotic keratitis. ${ }^{2}$

To protect onion harvesters from suffering ocular trauma and mycotic keratitis, workers should be well educated about the contributing factors of such disorders, as well as the protective measures they should take. It is strongly suggested that onion harvesters wear protective spectacles that afford full enclosure of their eyes. If exotic materials enter the eyes, workers should go at once to an ophthalmologist for proper diagnosis and treatment, instead of seeking medication from local pharmacies. The workers should learn that delay of proper medical care might result in blindness. Also, local ophthalmologists should be informed about this endemic ocular disorder and prepare for suitable treatment. With appropriate education of both workers and ophthalmologists, use of eye protection in fields, performance of personal hygiene, and provision of medical care, it is expected that the occurrence of mycotic keratitis in onion harvesters will be significantly reduced.

The authors gratefully acknowledge the farmers and the farmer cooperatives in Lin-Yuan, Heng-Chun, Shen-Chen, and Fun-Shen areas for their participation and assistance.

This study was funded by the Institute of Occupational Safety and Health, Council of Labor Affairs, Executive Yuan of Taiwan, Republic of China, IOSH88-H307.

Submitted for publication October 20, 2000; revised; accepted for publication June 29, 2001.

Requests for reprints should be sent to Dr. Ching-Wen Chang, Institute of Occupational Safety and Health, Council of Labor Affairs, Executive Yuan, \#99, Lane 407, Hengke Road, Shijr City, Taipei, 221, Taiwan, Republic of China.

\section{References}

1. Panda A, Sharma N, Das F, et al. Mycotic keratitis in children: epidemiologic and microbiologic evaluation. Cornea 1997; 16 (3):295-99. 
2. Thomas PA. Mycotic keratitis - an underestimated mycosis. J Med Vet Mycol 1994; 32:235-56.

3. Clinch TE, Robinson MJ, Brron BA, et al. Fungal keratitis from nylon line lawn trimmers. Am J Ophthalmol 1992; 114:437-40.

4. Ishibashi Y, Hommura S, Matsumoto Y. Direct examination vs. culture of biopsy specimens for the diagnosis of keratomycosis. Am J Ophthalmol 1987; 103:636-40.

5. Liesegang TJ, Forster RK. Spectrum of microbial keratitis in south Florida. Am J Ophthalmol 1980; 90:38-47.

6. Polack FM, Kaufman HE, Newmark E. Keratomycosis: medical and surgical treatment. Arch Ophthal 1971; 85:410-16.

7. Winchester K, Mathers WD, Sutphin JE. Diagnosis of aspergillus keratitis in vivio with confocal microscopy. Cornea 1997; 16: $27-31$.

8. Fincher RE, Fisher JF, Lovell RD, et al. Infection due to the fungus Acremonium (cephalosporium). Medicine 1991; 70:398-409.

9. Kinnas JS. Ophthalmic disease caused by a mycete of the giant cane. Br J Ophthal 1965; 49:327-29.

10. Byers JL, Holland MG, Allen JH. Cephalosporium keratitis. Am J Ophthalmol 1960; 49:267-69.

11. Cuero RG. Ecological distribution of Fusarium solani and its opportunistic action related to mycotic keratitis in Cali, Colombia. J Clin Microbiol 1980; 12:455-61.
12. Lin $\mathrm{SH}$, Lin $\mathrm{CP}$, Wang $\mathrm{HZ}$, et al. Fungal corneal ulcers of onion harvesters in southern Taiwan. Occup Environ Med 1999; 56: 423-25.

13. National Meteorological Station. Daily Meteorological Records in Heng-Chun Area in 1998, A-Table. 1999; (in Chinese).

14. Andersen AA. New sampler for the collection, sizing, and enumeration of viable airborne particles. J Bacteriol 1958; 76: 471-84.

15. Barnett HL, Hunter BB. Illustrated Genera of Imperfect Fungi. New York: Macmillan, 1987.

16. Larone DH. Medically Important Fungi: A Guide to Identification. New York: Elsevier Science, 1987.

17. Rosa RH, Miller D, Alfonso EC. The changing spectrum of fungal keratitis in south Florida. Ophthal 1994; 101:1005-13.

18. Chander J, Sharma A. Prevalence of fungal corneal ulcers in northern India. Infect 1994; 22:207-09.

19. Imwidthaya P. Mycotic keratitis in Thailand. J Med Vet Mycol $1995 ; 33: 81-82$.

20. Ainley R, Smith B. Fungal flora of the conjunctival sac in healthy and diseased eyes. Brit J Ophthal 1965; 49:505-15.

21. Hwang $\mathrm{YH}$, Chou EJ, Chang CW, et al. Suspended matters in onion farms and their potential effects on corneal injury of the harvesters. Arch Environ Health 2002; 57(1):78-84. 
Copyright of Archives of Environmental Health is the property of Heldref Publications and its content may not be copied or emailed to multiple sites or posted to a listserv without the copyright holder's express written permission. However, users may print, download, or email articles for individual use. 